\title{
Situated Sketching and Enactment for Pervasive Displays
}

\author{
Alix Ducros \\ Univ Lyon, Université Lyon 1, \\ CNRS, LIRIS, UMR5205 \\ F-69621, France \\ alix.ducros@liris.cnrs.fr
}

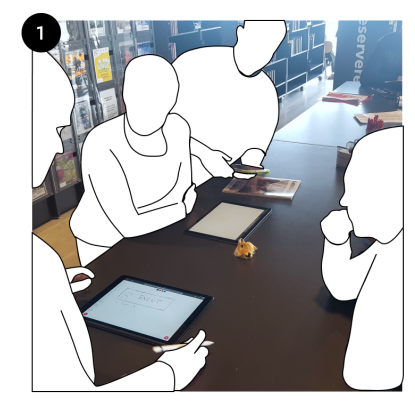

\author{
Clemens N. Klokmose \\ Aarhus University \\ 8200, Aarhus N, Denmark \\ clemens@cavi.au.dk
}

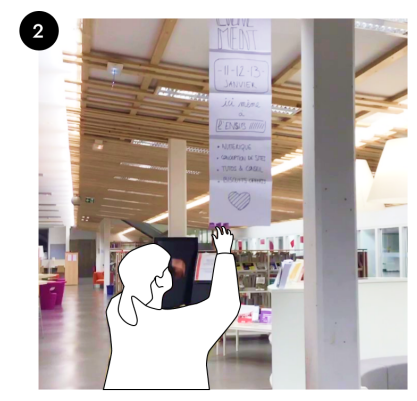

\author{
Aurélien Tabard \\ Univ Lyon, Université Lyon 1, \\ CNRS, LIRIS, UMR5205 \\ F-69621, France \\ aurelien.tabard@liris.cnrs.fr
}

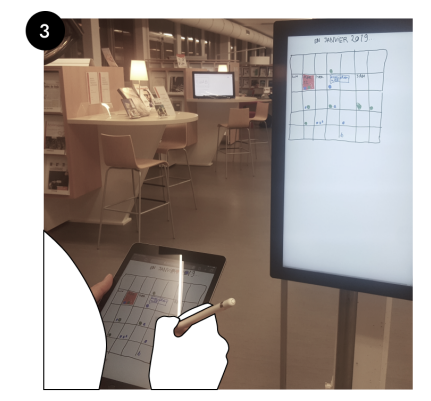

Figure 1: Situated sketching and enactment activities, 1. in a library, 2. with paper 3. with Ébauche

\begin{abstract}
Situated sketching and enactment aim at grounding designs in the spatial, social and cultural practices of a particular place. This is particularly relevant when designing for public places in which human activities are open-ended, multi-faceted, and difficult to anticipate, such as libraries, train stations, or commercial areas. In order to investigate situated sketching and enactment, we developed Ébauche. It enables designers to collaboratively sketch interfaces, distribute them across multiple displays and enact use cases. We present the lessons learned from six situated sketching and enactment workshops on public displays with Ébauche. And we present the results of a controlled study with 8 pairs of designers who used paper and Ébauche. We present the various ways in which participants leveraged the place, and how paper or Ébauche influenced the integration of their designs in the place. Looking at the design outcomes, our results suggest that paper leads to broader exploration of ideas and deeper physical integration in the environment. Whereas Ébauche leads to more refined sketches and more animated enactments.
\end{abstract}

\section{Author Keywords}

Sketching; Bodystorming; Ubicomp; Pervasive Displays.

Permission to make digital or hard copies of all or part of this work for personal or classroom use is granted without fee provided that copies are not made or distributed for profit or commercial advantage and that copies bear this notice and the full citation on the first page. Copyrights for components of this work owned by others than ACM must be honored. Abstracting with credit is permitted. To copy otherwise, or republish, to post on servers or to redistribute to lists, requires prior specific permission and/or a fee. Request permissions from permissions@acm.org.

ISS '19, November 10-13, 2019, Daejeon, Republic of Korea

(C) 2019 Association for Computing Machinery

ACM. ISBN 978-1-4503-6891-9/19/11 . .\$15.00

DOI: https: //doi .org/10.1145/3343055.3359702

\section{CCS Concepts}

-Human-centered computing $\rightarrow$ Interaction design process and methods; Ubiquitous and mobile computing design and evaluation methods; Empirical studies in interaction design;

\section{INTRODUCTION}

The advent of ubiquitous computing challenges interaction design practices. As computing becomes integrated in the environment, designers must consider the places in which they will deploy technology as being integral to the design $[8,14]$. Messeter argues that designing for a place must be "grounded on its social, cultural and material conditions but should also account for the dynamics of place that continually change these conditions" [21].

Public displays are one of the most visible signs of ubiquitous computing. They are present in the urban space, in train stations, in hospitals, and office spaces areas to name a few. Institutions such as modern libraries can easily be equipped with dozens if not hundreds of displays. Yet, deciding on the relevance of these displays, their location, and what content to meaningfully show on them is challenging. More broadly, complex socio-technical contexts are difficult to incorporate in designs.

The technological and methodological tooling for designing digital applications has matured over decades. It is less developed when we move away from device-centric applications and towards more distributed digital services such as content for public displays.

This is especially noticeable for tools supporting early explorations of design ideas. Bodystorming [5] and its variants have proven beneficial in exploring in-situ early design ideas through brainstorming and enacting scenarios of use [25]. 
Such practices are gaining in popularity, but their tooling is still limited to physical props and pen and paper to envision interactive systems. Recent work suggests that static sketching media in a situated context could hinder the exploration of rich interactive and context aware elements [3].

We designed Ébauche to investigate situated digital sketching and enactment practices. Ébauche is a collaborative sketching tool for public displays that supports bodystorming. We iteratively refined it through a series of design workshops in a library context. To identify how the environment shapes design ideas and how paper and digital sketching tools influence sketching and enactments, we conducted a study comparing two design contexts, using Ébauche or paper.

To identify how the environment shapes design ideas an how digital sketching tools influence sketching and enactments, we conducted a study where we compared the use of regular paper-based materials with Ébauche in designing content for public displays.

We found that paper led to broader exploration of ideas, and that it fostered the design of non-screen displays or nonstandard form factors, but also deeper physical integration in the environment. Whereas, Ébauche encouraged designers to iterate and refine their design ideas further, but also led to more sophisticated interactive enactments due to its support for simulating basic interactivity.

\section{RELATED WORK}

The issue of detachedness in design [31] remains an important design challenge for public displays and more broadly for Ubicomp, i.e., how can designs (and systems) be grounded in the social and cultural practices of a particular place, as well as their physical environment (e.g. [20, 21]). We survey research on techniques to do so, including bodystorming, enactment strategies and sketching.

\section{From body- to embodied storming}

Bodystorming covers a number of practices ranging from brainstorming activities in a given place, to more advanced enactment of ideas, with sketches, physical props, or reconfiguration of the surrounding space. Burns et al. can be credited for the term and popularizing the use of bodies and space in the design of digital systems [5]. In their case, brainstorming involved props in a studio, something that was already used in non-digital design practice.

One of the most striking aspect of bodystorming is how it has been used since its inception for multiple purposes: the development of empathy $[5,4]$, richer creativity through an enactive process $[5,25]$, more egalitarian contributions of ideas [5], better communication with peers and users [5], or clients [4], and even evaluating designs [4, 24]. Overall design activities happening in-situ over time help create a shared understanding of the context and facilitate the integration of ideas into existing practices [13].

Looking back at four design activities in which bodystorming was used, Oulasvirta et al. [25] observed that being in the place encouraged participants to consider contextual elements in their discussions. They also found that ideas generated during the bodystorming sessions tented to "stick" more after the sessions, and to be more inspiring. But they also remarked that preparing and running bodystorming sessions could be very time consuming, leading them to question the overall value of bodystorming.

Reflecting critically on past bodystorming practice, Schleicher et al. proposed to shift the focus of bodystorming, to its experiential and embodied nature. They argue that the real value is on experiencing the place and setting a "communicative mode of rapidly expressing ideas and proposals" [29]. This relates to the argument made by Márquez Segura et al. who emphasize playfulness and aesthetics in design. They proposed Embodied Sketching [22] as a way to "elicit creative physical engagement", through three different ways: bodystorming of ideas, which we already discussed, co-designing with users, and sensitizing designers which we both discuss below.

\section{Enactment Strategies}

Building upon bodystorming, several strategies have been proposed to explore designs through enactment, ranging from improvisation [9, 10], to actors playing scenes [23, 32]. With Experience Prototyping, Buchenau and Suri [4] developed enactment strategies using improvisation techniques with a professional actor involved as a supervising moderator, with a motivation close to our focus: empathizing and understanding context.

Enactment techniques can also enable design teams to evaluate systems by letting participants stage situations in a speculated setting $[24,2]$. Other strategies rely on domain experts staging interactions in an improvised manner [30]. Although it does not anchor the process in the "real" place, it builds upon similar staging practices to focus on the context and the use of prototypes.

\section{Sketching}

We are interested in the early design phase, and in the generative exploration of possible designs. Buxton distinguishes sketching and prototyping, with sketching dominating the early stages, and prototypes the later stages [6]. He characterizes sketches as being low cost, timely, produced in large quantity, and being disposable, in comparison to prototypes that are more focused. He notes that the process of sketching and the inherent ambiguities of the created artifacts stimulate creativity and foster the emergence of insights [6].

In collaborative settings, sketching proved to be beneficial. The sketching process itself can be effective at involving participants and generating insights [1]. And it has been used in participatory design contexts to explore new concepts with non-designers [7]. Some research prototypes explored collaborative sketching [33] and how to leverage pen-based interaction for creating prototypes and storyboards that can be tested rapidly [19]. Existing collaborative drawing tools such as Sketchtogether ${ }^{1}$ support collaborative sketching, but do not support the enactment / testing of the sketching in-situ. Interactive hand-drawn prototyping tools such as Marvel POP

\footnotetext{
${ }^{1}$ https://sketchtogether . com
} 

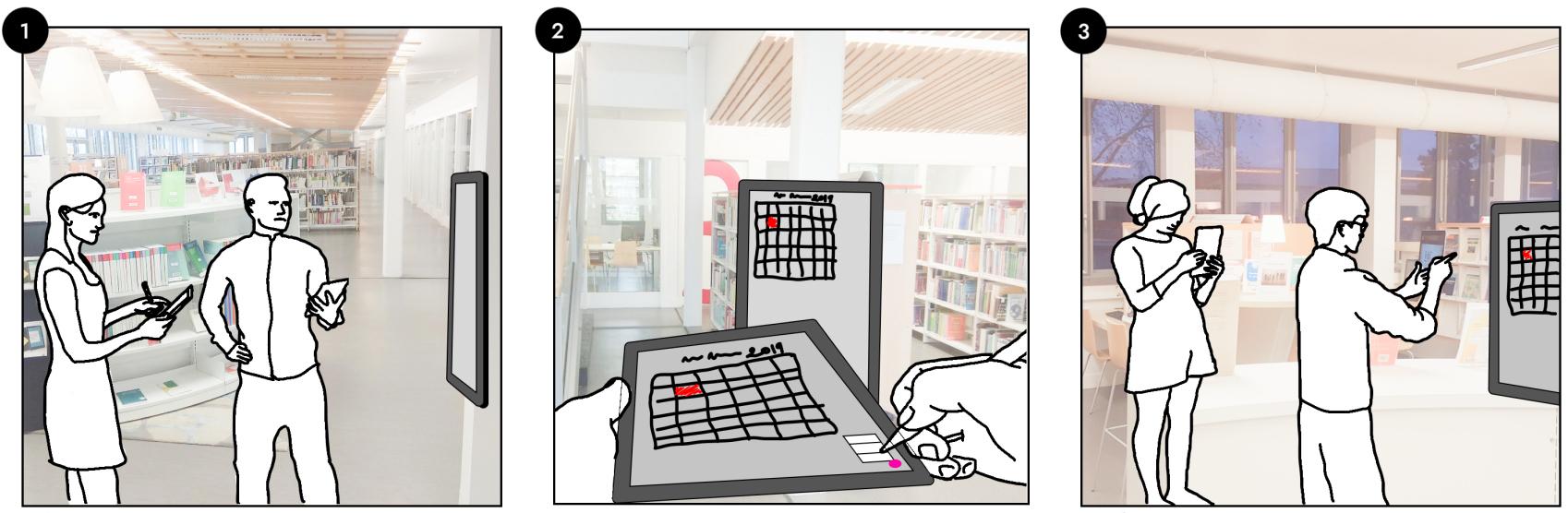

Figure 2: Ébauche. 1. Collaborative sketching on tablets, 2. Sending sketch to a display public, 3. Enactment (+ video recording)

support interactivity, but fail to support the enactment and in-situ deployment of sketches as well.

Sketching has an emphasis on low-tech and throw-away materials. Yet recent work suggests that static media may hinder the exploration of interactive and context-aware design opportunities [3]. Bressa et al. suggest that digital and hardware sketching tools could overcome some of these limits. For instance, the Gambit system [28] explored the ability to draw and visualize sketches on displays of different sizes (tabletop, tablet, smartphone). But Gambit only ran at a room level, and it did not support interactive previews and enactment. We seek to understand how richer sketching and enactment media can support more context sensitive design.

\section{ÉBAUCHE}

Based on our experience designing for public displays and previous research, we sought to explore how to better support

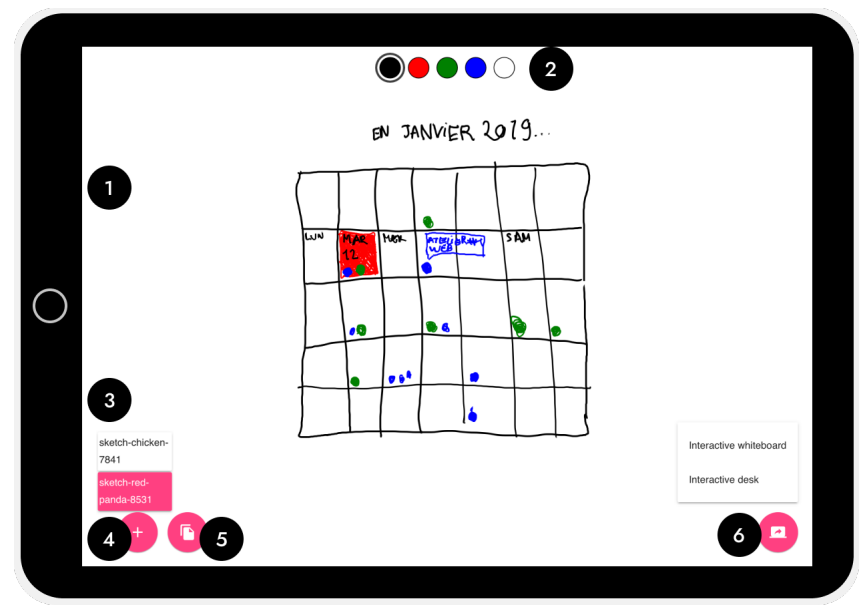

Figure 3: (1) The sketching area takes most of the screen space, (2) a color picker enables users to change the ink color, (3) the sketches created are listed on the left, (4) the "+" button creates a new sketch, (5) the button next to it duplicates the sketch currently opened. (6) The button to the right opens a list of nearby displays on which to push the active sketch. Inking works with a pencil, and touching deletes strokes. the early exploration of design ideas for interactive public displays. This led us to create Ébauche, a collaborative sketching tool for situated sketching that supports bodystorming and enactment. Through a series of design workshops, we refined Ébauche, assessing which features were most relevant.

\section{Ébauche features and use}

Ébauche is a digital sketching and enactment tool for pervasive displays (see fig. 3). Our initial goals with Ébauche were to: 1) Support collaborative sketching; 2) Enable seamless transfer and display of sketches on surrounding screens; 3) Facilitate enactments building upon the sketches.

With Ébauche, sketches are drawn on tablets and sent to displays that are situated in the environment with a single tap (see fig. 3.2). Designers start by sketching with a stylus in a free-form manner on their tablet (see fig. 3.1). The ink color can be changed via a palette and strokes can be deleted with a touch stroke. Designers can create new sketches (see fig. 3.4), or duplicate an existing ones at any moment (see fig. 3.5). Designers can push a sketch to any target display connected to Ébauche (see fig. 3.6).

In Ébauche, sketching is collaborative and changes made to a sketch are propagated in real-time to all the devices, both to tablets and to situated displays where they have been pushed. This enables collaborative drawing, but also critiques, and last minute refinements while enacting scenarios (see fig. 3.1).

When multiple sketches are pushed to the same target display, they are queued. Touching a display will move to the next sketch in the queue. This enables simulating interactions.

If a sketch has been pushed by mistake to a target display, it can be removed from the display by tapping on a small trash icon. This also enables designers to re-order sketches or rework their scenarios.

Ébauche is a Web application, opening its URL on any device will load the application, in a ready to use set-up. Ébauche is built on VueJS ${ }^{2}$ for the UI, and Webstrates [17] for the collab-

$\overline{{ }^{2} \text { https://vuejs.org (last accessed: July 8th 2019) }}$ 
orative sketches. We used Codestrates [26] as a development environment.

\section{A Technology Probe to explore Situated Sketching and Enactment}

We developed Ébauche as a research tool to investigate sketching and enactment practices in situ. We sought to create a simple, flexible, and adaptable tool, retaining the three goals of Technology Probes [15]: "the social science goal of understanding the needs and desires of users in a real-world setting, the engineering goal of field-testing the technology, and the design goal of inspiring users and researchers to think about new technologies." We iteratively refined Ebauche design in order to understand situated sketching and enactment, not demonstrate its benefits over other forms of bodystorming, enactment strategies, or paper based situated sketching:

We conducted several workshops with Ébauche to field test the technology, reflect and iterate on design choices, and see how it would influence sketching and scenario generation. At a user level, this led us to better understand collaboration, situated sketching workflows, and how contextual elements were considered in the design process. At an engineering level, we identified technical opportunities and related challenges. At a design level we could assess the benefits and drawbacks of Ébauche features, and iterate on their design.

\section{DESIGN WORKSHOPS WITH ÉBAUCHE}

Over a year, we conducted six design workshops, in which we used various versions of Ébauche. In the workshops we explored the use of pervasive displays in public spaces, primarily in library contexts [11],. They focused on how to convey, and interact with, information about past, present, and upcoming events in public libraries, but also with digital collections in the physical library. The workshops took place in three different libraries, in two European countries. All but one workshop lasted between $1 \mathrm{~h} 30$ and 2 hours, with approximately 1 hour of situated sketching activity. Authors were involved in all the workshops as organizers and as participants when stated so, the library researchers refer to the same persons. The librarians in workshops 3 and 4 were the same, and different from workshop 2 and 5. The librarians who took part in the workshops did not have significant experience with sketching on tablets, the other participants had some experience.

Workshop 1 involved two of the authors and two library researchers, in a university library. Four target displays were set up, although only one was used, and participants created six sketches.

Workshop 2 involved 25 librarians split in six groups (half of them using Ébauche, the others paper). Five screens were set up, three were used and participants created twelve sketches using Ébauche.

Workshop 3 and 4 involved two of the authors, two library researchers and six librarians. These two workshops were part of a series of six participatory design workshops. They took place in a public library in which it was challenging to set-up large screens, or take-over existing ones. Instead we relied either mobile tablets acting as mock public displays or paper.
During those workshops, 8 sketches were made using Ébauche and 13 using paper.

Workshop 5 involved the three authors and two HCI researchers, three librarians and two library researchers. They were split in two groups, one using Ébauche, the other using paper. This workshop was split in two sessions. A first session of $1 \mathrm{~h} 30$ was dedicated to ideation and a second one hour session was dedicated to situated sketching and enactment. This happened in another public library in which it was also challenging to set-up large screens or take-over existing ones. We relied on mobile tablets acting as mock public displays (see fig. 1.1).

Workshop 6 involved one of the authors and one library researcher. This workshop happened in the same location as workshop 1 and 2, it focused on representing digital collections in the physical space of the library and the visualization of events by leveraging the library space. The set-up consisted in one 27 in touch screen and four mobile tablets.

\section{Lessons learned and design iterations}

We used these workshops to reflect and adjust the design of Ébauche, but also the design process associated to it.

\section{Iteration 1. Coupling sketching tablets and target displays}

At first, we envisioned Ébauche as being used in close proximity to the displays being sketched for. As designers envisioned scenarios of use, they would go toward a display, which would open on their tablet a sketching area associated to that display, either manually or automatically (e.g. through proximity sensing). They could then start sketching. This workflow and its strong spatial constraint came in the way of participants.

Lesson 1: Sketch first, broadcast after. Our first trials showed that people tended to sketch first on tablets, and then only set-up the content on a public display. We hypothesize two reasons: (1) a wish to keep design explorations private until one is satisfied, and (2) the decision to display content on one screen or another is tied to scenarization, which tends to happen after an initial sketching and exploration phase, even when the scenario of use is already broadly defined.

\section{Iteration 2. Exploring embeddedness}

While running workshops in public libraries during opening hours, it proved difficult to take over existing screens, or reorganize the space. We also noticed the need to explore unconventional display size, shape or location. E.g. content projected on the floor, large banner like displays hanging from the ceiling, etc.

We explored two alternatives that enabled designers to better embbed digital sketches in their environment and explore display for factors more freely:

1. We introduced the ability to take and add pictures as a background to sketches, which enabled to embed screens in a variety of ways on the picture (see fig. 4-left).

2. We explored the ability to attach sketches in an augmented reality (AR) fashion to $\mathrm{QR}$ codes laid out in the environment. The sketching tablet enabled designers to push sketches to $\mathrm{QR}$ codes, like they could do with target displays, an 

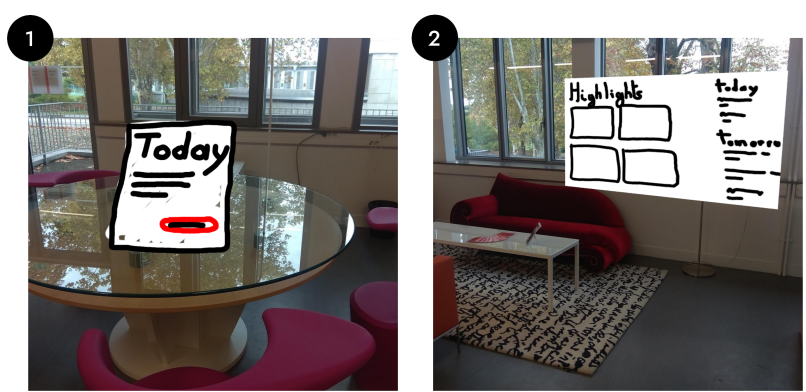

Figure 4: Left : sketch drawn on a still picture. Right : augmented reality display.

extra feature enabled designers to switch to an AR mode to preview the sketches overlaid in the environment (see fig. 4-right).

Lesson 2: Augmentation strategies make it difficult to incorporate sketches in enactments. While both strategies enriched the expressivity of Ébauche, they both presented problems in the enactment phase. It was challenging to enact a scene with the sketches "inside" the tablet (drawn upon an image) or only "virtually" present (with AR).

When sketches only can be viewed on the tablet, either drawn or in $\mathrm{AR}$, the video recording of the enactment becomes more challenging. Participants could not enact any interaction with the content in AR or on a drawn image. In one workshop, participants even forgot about the sketches that were not physically present in space, and skipped the related step in their enactement without noticing. In practice, such a set-up would require more sophisticated video editing such as [18] or a set-up with AR glasses.

\section{Iteration 3. Leveraging digital benefits}

In the last iteration, we refined Ébauche with improvements to leverage the benefits of digital sketches, and remove some practical hurdles. We introduced the ability:

1. to duplicate sketches,

2. to delete content that had been pushed to a screen, and

3. to simulate interaction by looping through sketches pushed to the same screen.

Lesson 3: sketch duplication and simulating interaction streamlines design exploration and enactment. The three features depart most from what is possible with paper sketches, alongside the ability to draw on a sketches already set-up on a display. These features, were the ones we received most feedback on, and once introduced made the use of Ébauche much more seamless.

\section{SITUATED SKETCHING AND ENACTMENT STUDY}

To understand how the sketching medium and the environment influence the ideas, the sketches, and the enactments produced by designers, we conducted a study in two locations using paper or Ébauche. We take inspiration from Jensen's et al. study of digital remediation of post-its [16], but shift the question to another design activity: sketching and enactment, and analyse the influence of both the tools and the environment on design outcomes.

\section{Pilot studies}

We conducted four pilot studies, with four pairs of designers, to explore the impact of study factors on the design process and its outcome. We tested the following factors:

1. Situated vs. non situated design activity. Our initial hypothesis and most work on bodystorming assumes the inherent benefits of being in-situ. However, as we saw in the workshops we conducted, designing in-situ comes with a set of challenges in taking over a space for design activities. We aimed at testing whether it would make sense to compare designing in-situ to designing in a remote space.

In this pilot a pair of designers worked on one scenario in-situ with Ébauche, and on another scenario with Ébauche at a desk in an office, after they visited the space. The main challenge here was defining a study set-up in which the non-situated condition was realistic enough, e.g., visiting the space and only conducting the design activity a week later. This proved difficult to conduct and control for, but could be explored in future research.

2. Ébauche vs. paper. We used Ébauche as a probe to investigate situated sketching and enactment activities. With the four pilot groups we compared a paper-based activity to Ébauche, to identify whether we observed variations (and invariants) in the design process, and in the design outcomes. Preliminary results hinted at paper fostering more variations and breadth in the exploration, whereas Ébauche tended to be more in-depth exploration of a design idea. We also validated that Ébauche could be appropriated quickly without usability issues.

3. Four design scenarios. We sought to identify which design scenarios were most promising to test. The scenarios were set in four different settings: two in a large open space (a small library) and two in smaller spaces (a smart-room and an exhibit space). For each scenario we created a design brief: (1) designing interactive services to convey information about digital collections in a library, (2) to convey information about library events and activities, but also (3) augmenting a smart-room for remote participation, and (4) augmenting an exhibit with relevant digital resources. Two scenarios, the communication about events in the library, and the remote collaboration in a smart-room, were the ones that fit best the space used in the studies, and participants also appropriated the design briefs rapidly on these two topics.

The pilots helped us to identify two scenarios, confirm the relevance of comparing paper and Ébauche, and to focus on situated sketching, leaving out the non-situated condition.

\section{Main study}

Based on the pilots insights, we conducted a study to investigate situated sketching and enactment in two situations: a smart-room or a library, with two tools: paper or Ébauche.

\section{Participants}

We recruited 16 interaction designers: eight pairs of design students at a masters level (age 20-23) and one pair of profes- 
sional designers (age 24 and 28). All had sketching experience and 11 had experience in designing for public displays.

\section{Procedure}

The study lasted approximately $1 \mathrm{~h} 45$. It started with ten minutes of introduction, and a short questionnaire about previous design experience. After the introduction, participants had a five minutes training task with both paper and Ébauche, which consisted of reproducing a UI sketch, placing the sketch either on a wall or on a display, enacting a tap on a button, and capturing this through a photo or video. We answered any questions that arose.Participants were then invited to conduct two situated design tasks, in two different situations. We teamed participants in pairs to reflect a collaborative design session. The order in which participants used the tools and the situations were counterbalanced across the groups.

Each task lasted 30 minutes using either paper or Ébauche, they could not switch tools during a given task. Participants had five minutes to read a design brief and go through design material (a broad scenario, and resources related to previous user-research), they could ask questions to clarify the goals, the procedure, or the expectations. Then participants were invited to generate ideas and sketch together in the space they were in. After 15 minutes we handed them a tablet with the camera application set-up in order to shoot an enactment in the remaining ten minutes. Participants could keep sketching, as long as they recorded the enactment within the time left. In case participants needed extra time to finish shooting the video, we allowed up to three more minutes. Participants had a break before moving to the second task using the tool they did not use already, in the other situation.

Once both tasks were completed, participants filled a second questionnaire focusing on their design process and their experience. Then they presented to us their video enactment, which was followed by a semi-structured interview of 15 to 30 minutes. Due to the length of the tasks we did not deem it feasible to perform a third task with mixed tools (as, e.g., done in [12]).

\section{Tasks and situations}

Participants had the task to design collaboratively for two different situations: a library and a smart-room. When Ébauche was used, we set-up in advance three public displays in the environment (see fig. 5 and 6).

The library task consisted of designing public displays that enables patrons to discover the events that happened, are happening or are going to happen in a library. We conducted this task in a university library within a small information science school (see fig. 5 for the set-up and layout).

The smart-room task consisted of designing a system that would allow remote collaborating students to participate in group tasks such as brainstorming, document analysis or preparing a group presentation. We conducted this task in a room dedicated to group work equipped with a whiteboard, modular desks and a 43 inches interactive display (see fig. 6 for the set-up and layout).

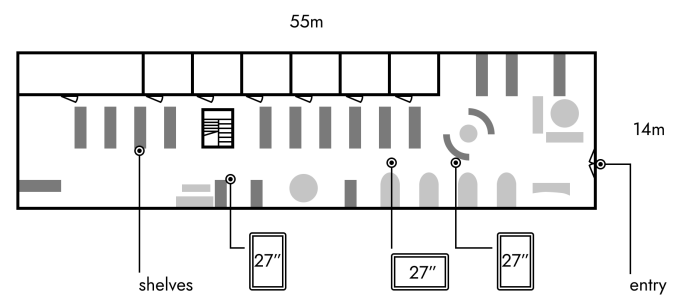

Figure 5: Library situation

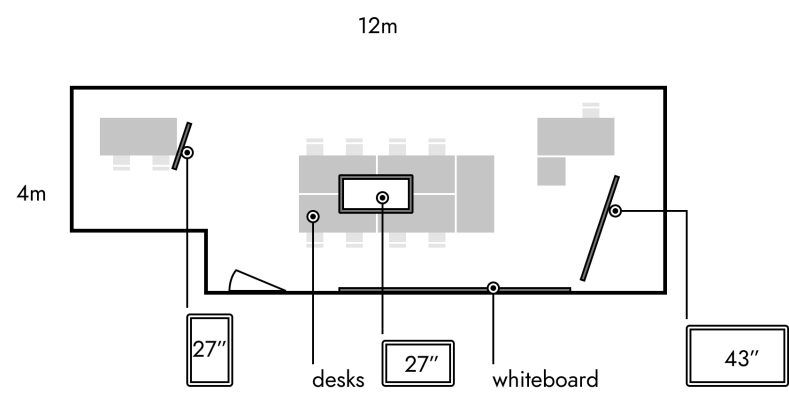

Figure 6: Smart-room situation

\section{Materials}

Participants were given a five page leaflet for each task containing: a presentation of the context they have to design for, design goals, a generic user story in the context, and some examples events for T1. Participants were told the design goals and the user story were for inspiration only and they had the possibility to explore other ideas. The enactments were recorded using an iPad.

In the task using paper, we provided participants with A4 and A3 white paper, tape, masking tape, scissors and pens (blue, green, red, black and white).

In the task with Ébauche, each participant was given an iPad with a pen. Three large touchscreens were installed in the environment and two tablets (10in) could be placed at the participants will. The 27 in displays had a size close to A3 sheets, while the tablets were similar in size to A4.

\section{Data Collection and analysis}

Participants answered a survey before and after the study. The first survey focused on background information, especially about participants' experience with bodystorming, public display design and, familiarity with sketching with tablets or paper. The final survey focused on participants' perception of the design process in both activities, the tools and the situation they designed for.

After both tasks were completed, we debriefed participants. They started by presenting the video of their enactment (generally taking 10 minutes) and we followed with a semi-structured interview of 20 to 25 minutes during which we went back to:

1. the design concepts the participants created and how elements from the environment were incorporated,

2. their perception of the design process during the activity, and how did they collaborate. 
We collected, reviewed and analyzed the video enactments and the debrief interviews. The first author analyzed and coded them in order to identify and quantify key elements in the design concepts such as the interactions enacted, the number of states of screens, the use of contextual elements, etc. To clarify participants' motivations or the influence of environmental factors, we went back to the video recordings of the design activity, which we recorded using two wide angle action cameras.

\section{Limitations}

Participants could have benefited from more time to explore the space, and to explore ideas. However, all the participants were used to generating designs under time constraints and they managed to produce one enactment or more per situation.

We could not control for the presence and influence of external people in the library, we discuss their (lack of) influence in the results. This may be due to the late afternoon time slot that we used for the study, which was relatively quiet.

\section{RESULTS}

In the following, a sketch refers to a drawing on a tablet or on paper. A design idea refers to one or many sketches centered on one idea, device, or screen. And a scenario refers to several design ideas chained together to illustrate a use case.

The participants enacted 25 scenarios in total (mean=1.6, $\mathrm{sd}=0.9$ ) per situation (table 1 ). The video enactments lasted from a few seconds to three minutes.

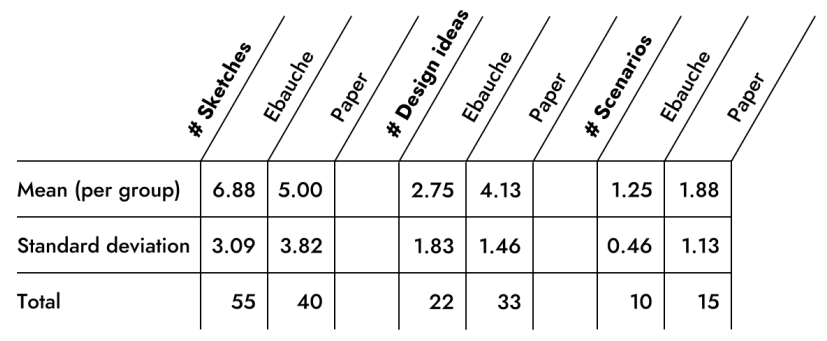

Table 1: Sketches, ideas and scenarios created

\section{Exploring the space}

\section{Considering the space in the design}

Before starting to sketch, all the groups explored their surroundings. In the large open space of the library they moved around to explore the space, whereas in the smart-room they could orient themselves at a glance.

In both situations, participants explored more ways to take advantage of their surroundings with paper, 25 environmental features leveraged (mean $=3,1, \mathrm{sd}=1,2$ ), against 17 using Ébauche (mean=2.1, sd=1.3). Environmental features include structural features such as a wall, permanent furniture such as shelves, and more movable objects like screens, books and lamps. Overall, participants felt it was easier to leverage environment features using paper than with Ébauche (see fig7).

The library setting was particularly inspiring for the participants and they focused their attention on environmental features in mostly two places: the entrance (see fig. 1.2 and 1.3),

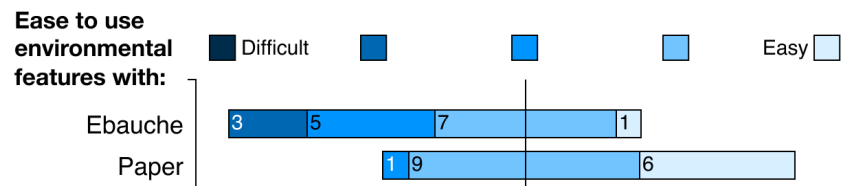

Figure 7: Ease to leverage environmental features with Ébauche and paper. Answers on a Likert scale from 1 (Difficult) to 5 (Easy).

and the collections area. There, they could develop scenarios depicting the arrival of a library user and his wandering through bookshelves.
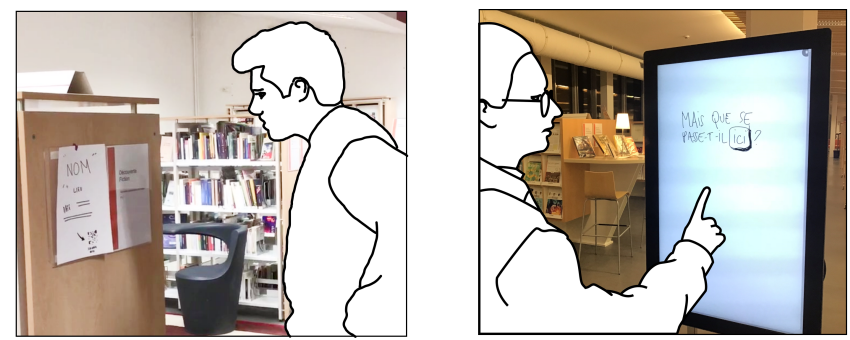

Figure 8: Left: Interaction with a bookshelf. Right: Interaction with the entrance screen.

Seven groups decided to work on scenarios at the entrance of the library. They were particularly inspired by a vertical screen already installed there, and a pillar close to the doors that was suitable for prototyping.

Five groups worked with envisioning how users could navigate through the shelves. They imagined using the sides of the shelves to display related information. Here, the use of the space was opportunistic and participants did not pay attention to the theme of the shelves. The sides of the shelves were only used with the paper prototypes given the affordance of paper to be stuck on surfaces (see fig.8).

In the paper condition both in the library and the smart-room participants used paper sketches or tape on the floor to mark areas relevant to the designs. In the smart-room, it consisted in giving remote collaborators a physical presence while practicing for an oral presentation (see fig. 9.2).
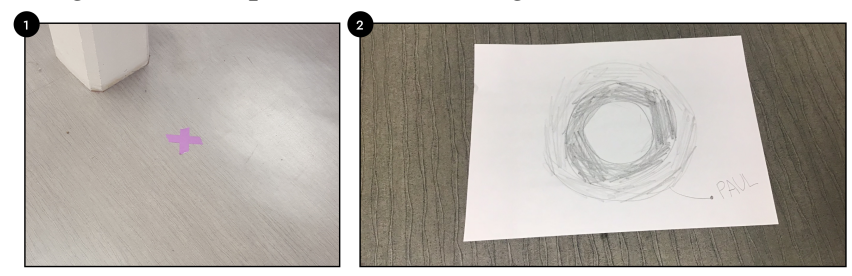

Figure 9: Marks left on the ground by participants.

\section{Unused spaces and devices}

Not all spaces were treated equally in the library. The entrance and the collections area inspired most design ideas to the participants, whereas the information desk and the copy and printing space led to only two design ideas. The lounge area with sofas close to the entrance was not used at all by the participants. Out of the seven times participants used screens, 
the entrance's vertical screen was used four times, and the horizontal screen, installed a bit further was never used in the enactments.

Unlike what we observed during the previous workshops and pilots, the tablets we handed to participants as movable/ad-hoc displays were almost not used. They were used twice in the smart-room, and not at all in the library, although our workshops showed that they lend themselves well to integration on shelves. In the smart-room and the library, however, group $G$ and $F$ respectively used their own sketching tablets in the enactment to showcase design ideas.

\section{Map sketches}

During the study, in the smart-room situation with Ébauche, group $\mathrm{C}$ and $\mathrm{G}$ created maps. Those did not represent useful content for enactment, but rather high level ideas to discuss or graphical depiction of the idea integrated in space (e.g. fig. 10). Group $\mathrm{C}$ was especially proficient regarding map production and made five different maps. Three of them formed a sequence used to picture the activity of users in space and how they would move during three different steps. The other maps listed devices and users involved in the design idea as well as their placement in the room. We did not observe any instance of this in the previous workshops we conducted.

Maps as well as other intermediate sketches were useful to the thought and discussion process of designers, as stated by group D : "The first thing we did was to draw a diagram [...], that was not used after, but we needed it to explain the process.".

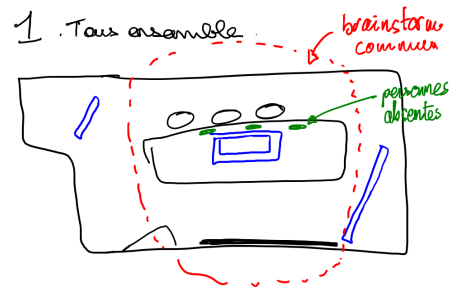

Figure 10: One example of meta sketch from group C

\section{Enactments}

Enacting scenarios enables designers to get a better understanding of how their ideas would unfold in practice. Ébauche tended to encourage more complex scenarios and more interactive details.

\section{Use of space in the enactments}

The majority of scenarios focused on one place at a time. Leveraging more than one place often meant creating multiple video enactments. Nonetheless, in seven enactments, participants embedded their design ideas in representations of typical user activities of the place, leading them to depict a journey through several places in a same scenario. Group $\mathrm{C}$ was particularly proficient in that manner, their three enactments followed the user from her entrance in the library, through multiple places to then pick a book in the end. Groups $A$ and $B$ on the other hand focused only on the entrance, but their scenario involved a screen that would react to the movements of the incoming user by progressively displaying its content.
In the smart-room situation, the constrained space was less inviting to envision rich navigation in space. The two scenarios leveraging space we could observe highlighted how a user shifted between activities by moving around the room.

\section{Interactivity in the enactments}

If we do not consider group F (discussed below), we observe a mean ratio of UI change per design idea ${ }^{3}$ using Ébauche of 0.98 , while using paper the mean ratio is equal to 0.39 , with standard deviation of respectively 0.66 and 0.34 . These results suggests that Ébauche led to design ideas that were more animated than those with paper. Most of these state changes were in response to some form of interaction, but two groups also leveraged the collaborative drawing features of Ébauche to design and enact with interfaces that were changing through context awareness, i.e., without input from the user.

Group F acted differently from the others: right after the training tasks, using paper on their first design activity they filmed a scenario with more than seven state changes. They were the only group that came to us with a question during the task, it was: "Can we use Ébauche instead of paper?" They explained it by their need to draw progressively, and to duplicate content. While this is an extreme case, participants found sketches easier to modify with Ébauche than with paper, and also deploying/setting up a sketch with Ébauche rather than paper (see fig. 11).

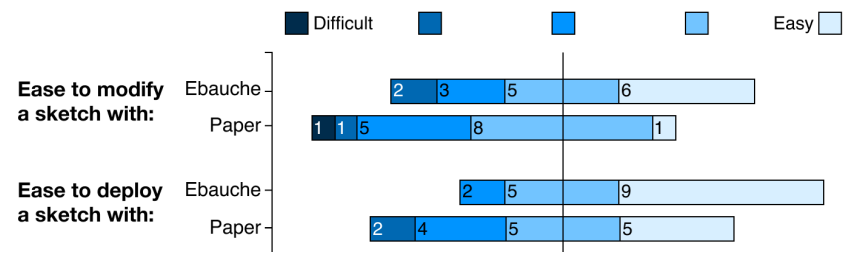

Figure 11: Ease of modification and deployment with both tools. Answers on a Likert scale from 1 (Difficult) to 5 (Easy).

\section{Using contextual resources in the enactments}

Among the 42 environmental features used in the enactments, nine of them were objects found in the place. Their use enabled designers to ground the enactment of scenarios in the activity context. Books were a popular asset and represent $50 \%$ of those. They were used to enact activities typical to the library: group $\mathrm{C}$ enacted a scenario where a user searches a document, group D proposed printing an augmented ticket when borrowing books, group F imagined a device scanning books, etc. Other elements, like chairs in the smart-room were leveraged by group E to serve their evolving workplace idea.

\section{Sketches}

\section{Paper led to more design ideas}

Participants explored more design ideas with paper than with Ébauche (33 vs. 22 , mean=4.1 vs. 2.75 , sd=1.8 vs. 1.5$)$, which led them to envision more scenarios in the allocated time with paper: overall 15 scenarios using paper and ten using Ébauche. Participants also considered that paper supported creativity

\footnotetext{
${ }^{3}$ computed using the third degree Taylor expansion of the (ui_change)/(design_idea) variable
} 
better, six preferred paper, two Ébauche, and eight considered both equal (see fig. 13).

\section{Ébauche sketches are refined over iterations}

Except group E, all the groups created more sketches with Ébauche than with paper. In total, Ébauche led to the creation 55 sketches against 40 with paper. Of these sketches, participants used 25 of them in the enactments with Ébauche, and 33 with paper.

We looked at iterations, i.e., modifying a sketch or redoing part of it. Participants using paper did not iterate on their design ideas at all once a sketch was done, it was used as is. We also did not record participants erasing anything on paper, or replicating part of a sketch to explore an alternative. With Ébauche, five groups out of eight did significantly modify ${ }^{4}$ their sketches before using them in their video enactments and all of them used the erasing capabilities. While most sketches only needed to be modified once, one sketch from group A benefited from four iterations (see fig. 12) and one sketch from group E went through three iterations before being used.

Ébauche also enabled two groups to work synchronously on the same sketch. In the library, Group A used a shared display to try four different versions of design idea, although they did not use it in the video enactment. Group C used the collaborative drawing feature of Ébauche to work on diagrams in the smart-room situation.

The real-time distribution of sketches proved to be useful for collaborating while looking at a target display. Rather than focusing on one's tablet, participants could look at the large display and make quick changes on their tablet. For updating target displays on the fly, the real-time nature of Ébauche enabled participants to quickly simulate a change during the enactment phase without preparing all the sketches beforehand.

\section{Paper, Ébauche and design ideas}

Screens already set-up framed the design ideas of participants. As one participant from group A told us, "the presence of the screens made me want to try to integrate all of them in a single scenario", and one from group E: "we had a tablet, so we thought we should create something digital". All but one of the 22 design ideas created using Ébauche were screenbased and mostly leverage the screens already set-up. This lack of usage of the tablets is different from what we observed during the pilots and the workshops we conducted before with more participants. Here, when they did use a tablet to display a sketch, they preferred to use the sketching one, which is something we already observed in the workshop. This means that the sketching UI was still visible and that simulating interaction was not available, but the speed and convenience of using the device was considered more important.

On the other hand paper offered more freedom regarding the nature of the sketches and in their positioning. With paper, nine design ideas out of the 33 represented media or devices not screen-based, e.g., posters, bookmarks, or even drones.

\footnotetext{
${ }^{4}$ We considered a significant modification the erasing of at least one third of a sketch followed by the addition of new elements.
}

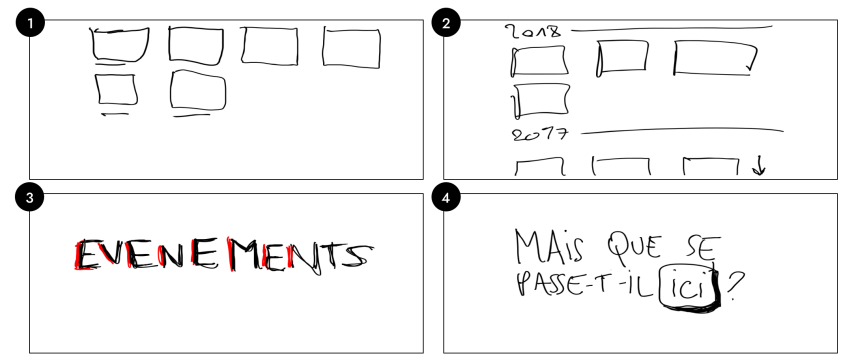

Figure 12: Four iterations of a design idea from group A

The malleable nature of paper also allowed participants to cut it or fold it to fit their needs. As participants from group A and $\mathrm{B}$ put it during the interview "Without paper, we were more limited in our range of possibility". In the final survey, participants also tended to consider paper as better supporting creativity (see fig. 13).

\section{Familiarity with paper as a sketching medium}

Although participants expressed interest in the possibilities offered by Ébauche. During the interviews, they insisted on their familiarity with paper and how they felt more comfortable using it over Ébauche. All the participants already had extensive experience with sketching on paper, and the training with Ébauche lasted less than 5 minutes, which seemed enough. As participants from group E and G put it "Collaborating with tablets was not easy right away" and "We were more comfortable with paper sketching rather than with tablet [...] which are not the one we are used to." Another reason would be that they felt more in control with paper as stated by group $\mathrm{E}$ and $\mathrm{H}$ "Quickly materializing ideas, and mixing them, it is simpler on paper" and "We have more control over paper."

Despite the comparative disadvantage Ébauche could have, we did not get negative impressions about the tool and participants were rather pleased about its opportunities, one participant from group $\mathrm{C}$ was particularly enthusiastic "We are used to paper, but the tablet tool is quite extraordinary I think, it has a lot of potential."

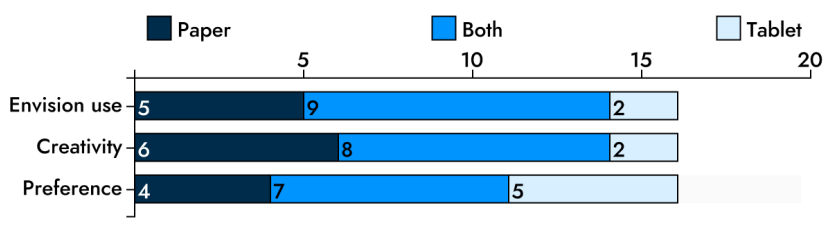

Figure 13: Participants' preference between paper and Ébauche in respect to envisioning their idea, supporting creativity, and overall preference.

\section{DISCUSSION}

We reflect on the workshops and study, and their implications for situated design activities, ranging from body/embodied storming, to situated sketching, and enactments.

\section{Situating design}

Sketching and enacting scenarios in-situ was a source of inspiration for participants, they explored the place and took note of interesting design opportunities such as spatial features, 
objects, and activities that were taking place. All groups from the study leveraged at least one environmental feature in their enactment and five groups created scenarios that unfolded in space, leveraging different devices and locations through the enactments.

Real world places are, however, not always accessible for doing design activities, or only for short periods of time, and often involving an extra preparation cost [25]. This was particularly true for workshops three and four, where we grounded the process in the main public library of the city and could only make use of the space during one hour before opening to the public. Setting up Ébauche with big displays was an additional challenge in this context.

There is more than "being there" to situate design. As we could observe during the study, the use of maps gave participants another way of envisioning the space and supported their discussion. During workshops, drawing upon photos taken with Ébauche was also a strategy used to situate design while being away.

Both in the workshops and the study, participants explored the space first, then sketched in a fixed location, before trying out their enactment and "deploying" their sketches in the space. If participants did not move while sketching, they still benefited from a rapid access to the place. We could imagine splitting place exploration from sketching, with a preliminary capture of pictures and maps of the place to start brainstorming, before going there to adjust the design and enact scenarios.

We should also consider that situated design relies on a deep understanding of the social context of the place and the activities that occur there. During the study, participants had a tacit knowledge of the activities that take place in a library or in a working room. During the workshops that involved professional librarians we were able to leverage their expert knowledge about the place. Knowing areas of interest in the library, they encouraged the use of an "ephemeral library" shelf, they also revealed the existence of curated content that is usually not publicly accessible, but could be used in the design. Librarians were also much more aware of day-to-day challenges of deploying technology in a library such as locations with the highest visits, or security challenges related to public screens.

\section{Breadth of ideas vs. refined sketches}

We observed that participants explored fewer design ideas with Ébauche, and that participants were mostly sticking to displays already installed in their environment. However, they created more sketches with Ébauche than with paper. From our observations and the logs analysis, it appears that participants iterated on design ideas not only by modifying the corresponding sketch, but also by creating other sketches for the same idea. While there was only one sketch with no iteration per design idea using paper, Ébauche encouraged the creation of multiple sketches and iterations for a same design idea.

In our study, paper encouraged broader exploration of design ideas, and led to more use of environmental features. However the ease to create and modify sketches offered by Ébauche enabled the participants to explore screen-centric design ideas more in-depth and refine them quickly.

In practice both media seem complementary. Similarly to more classical interface design, paper appears to be a good medium in the early exploration, and digital tools such as Ébauche more suited for more focused iterations where interactivity and context awareness are explored.

\section{CONCLUSION}

Designing ubicomp environments is still challenging, especially to ensure relevance to contexts of use, in situations involving open ended activities. Suchman talks about detachedness in design as problematic, referring to the dissociation between where design concepts are envisioned, and where they will be deployed [31].

In this paper we developed a probe and used it to better understand how digital design tools could influence situated design activities, especially early in the design process, when open explorations and rapid iterations are important. As bodystorming advocates already shown, being situated also has an experiential value for designers, it helps sensitize them to a multitude of local issues and might reveal unexpected insights or design opportunities [27]. We also pointed out the challenges faced by in-situ design activities and identify alternatives to "being there" in situated design.

We proposed Ébauche, a situated sketching tool for pervasive displays that supports bodystorming: envisioning how a service could be used by enacting its use in place. Its design was refined through multiple iterations and deployments in design workshops. We conducted six design workshops over the course of a year to refine Ébauche design, and envision novel digital services for libraries, with various stakeholders.

We presented a study comparing how paper and Ébauche influence design processes and outcomes in two different situations. Being situated led participants to leverage their environment, but they incorporated contextual elements in their designs differently with paper and Ébauche. Paper led to a broader exploration of ideas, that it fostered more non screen-centric ideas, and more non-standard display form factors, but also deeper and more varied physical integration in the environment. Ébauche led to more refined sketches, supporting designers in iterating on their design ideas, thanks to its ability to easily create, duplicate and modify sketches. Enactments made using Ébauche pictured richer interactions between users and devices, thanks to its support for simulating basic interactivity.

\section{ACKNOWLEDGMENTS}

We thank our project partners, the numerous workshop participants for their engagement, the workshop hosts, and the students from DSAA Villefontaine who participated to the study. This work was conducted within the JPI Urban Europe EU 693443 with support from ANR and Innovation Fund Denmark 5123-00007B. 


\section{REFERENCES}

[1] Kheir Al-Kodmany. 1999. Using visualization techniques for enhancing public participation in planning and design: process, implementation, and evaluation. Landscape and Urban Planning 45, 1 (Sept. 1999), 37-45. DOI : http://dx.doi.org/10.1016/S0169-2046(99)00024-9

[2] Inna Belinky, Joel Lanir, and Tsvi Kuflik. 2012. Using Handheld Devices and Situated Displays for Collaborative Planning of a Museum Visit. In Proceedings of the 2012 International Symposium on Pervasive Displays (PerDis '12). ACM, New York, NY, USA, Article 19, 6 pages. DOI :

http://dx.doi.org/10.1145/2307798.2307817

[3] Nathalie Bressa, Kendra Wannamaker, Henrik Korsgaard, Wesley Willett, and Jo Vermeulen. 2019. Sketching and Ideation Activities for Situated Visualization Design. In Proceedings of the 2019 on Designing Interactive Systems Conference (DIS '19). ACM, New York, NY, USA, 173-185. DOI: http://dx.doi.org/10.1145/3322276.3322326

[4] Marion Buchenau and Jane Fulton Suri. 2000. Experience Prototyping. In Proceedings of the 3rd Conference on Designing Interactive Systems: Processes, Practices, Methods, and Techniques (DIS '00). ACM, New York, NY, USA, 424-433. DOI : http://dx.doi.org/10.1145/347642.347802

[5] Colin Burns, Eric Dishman, William Verplank, and Bud Lassiter. 1994. Actors, Hairdos \& Videotape-Informance Design. In Conference Companion on Human Factors in Computing Systems (CHI '94). ACM, New York, NY, USA, 119-120. DOI : http://dx.doi.org/10.1145/259963.260102

[6] Bill Buxton. 2010. Sketching User Experiences: Getting the Design Right and the Right Design. Morgan Kaufmann.

[7] Oya Demirbilek and Halime Demirkan. 2004. Universal product design involving elderly users: a participatory design model. Applied Ergonomics 35, 4 (July 2004), 361-370.

[8] Paul Dourish. 2004. What We Talk About when We Talk About Context. Personal Ubiquitous Comput. 8, 1 (Feb. 2004), 19-30. DOI :

http://dx.doi.org/10.1007/s00779-003-0253-8

[9] Elizabeth Gerber. 2007. Improvisation Principles and Techniques for Design. In Proceedings of the SIGCHI Conference on Human Factors in Computing Systems (CHI '07). ACM, New York, NY, USA, 1069-1072. DOI: http://dx.doi.org/10.1145/1240624.1240786

[10] Elizabeth Gerber. 2009. Using Improvisation to Enhance the Effectiveness of Brainstorming. In Proceedings of the SIGCHI Conference on Human Factors in Computing Systems (CHI '09). ACM, New York, NY, USA, 97-104. DOI :

http://dx.doi.org/10.1145/1518701.1518718
[11] Carla Gröschel, Peter Dalsgaard, Clemens N. Klokmose, Henrik Korsgaard, Eva Eriksson, Raphaëlle Bats, Aurélien Tabard, Alix Ducros, and Sofia E. Serholt. 2018. PARTICIPATE: Capturing Knowledge in Public Library Activities. In Extended Abstracts of the 2018 CHI Conference on Human Factors in Computing Systems (CHI EA '18). ACM, New York, NY, USA, Article LBW060, 6 pages. DOI :

http://dx.doi.org/10.1145/3170427.3188605

[12] Jonathan Haber, Miguel A. Nacenta, and Sheelagh Carpendale. 2014. Paper vs. Tablets: The Effect of Document Media in Co-located Collaborative Work. In Proceedings of the 2014 International Working Conference on Advanced Visual Interfaces (AVI'14). ACM, New York, NY, USA, 89-96. DOI : http://dx.doi .org/10.1145/2598153.2598170

[13] John Halloran, Eva Hornecker, Geraldine Fitzpatrick, Mark Weal, David Millard, Danius Michaelides, Don Cruickshank, and David De Roure. 2006. Unfolding Understandings: Co-designing UbiComp In Situ, over Time. In Proceedings of the 6th Conference on Designing Interactive Systems (DIS '06). ACM, New York, NY, USA, 109-118. DOI : http://dx.doi.org/10.1145/1142405.1142423

[14] Steve Harrison and Paul Dourish. 1996. Re-place-ing Space: The Roles of Place and Space in Collaborative Systems. In Proceedings of the 1996 ACM Conference on Computer Supported Cooperative Work (CSCW '96). ACM, New York, NY, USA, 67-76. DOI : http://dx. doi.org/10.1145/240080.240193

[15] Hilary Hutchinson, Wendy Mackay, Bo Westerlund, Benjamin B. Bederson, Allison Druin, Catherine Plaisant, Michel Beaudouin-Lafon, Stéphane Conversy, Helen Evans, Heiko Hansen, Nicolas Roussel, and Björn Eiderbäck. 2003. Technology Probes: Inspiring Design for and with Families. In Proceedings of the SIGCHI Conference on Human Factors in Computing Systems (CHI '03). ACM, New York, NY, USA, 17-24. DOI : http://dx.doi.org/10.1145/642611.642616

[16] Mads Møller Jensen, Roman Rädle, Clemens N. Klokmose, and Susanne Bodker. 2018. Remediating a Design Tool: Implications of Digitizing Sticky Notes. In Proceedings of the 2018 CHI Conference on Human Factors in Computing Systems (CHI'18). ACM, New York, NY, USA, Article 224, 12 pages. DOI : http://dx.doi.org/10.1145/3173574.3173798

[17] Clemens N. Klokmose, James R. Eagan, Siemen Baader, Wendy Mackay, and Michel Beaudouin-Lafon. 2015. Webstrates: Shareable Dynamic Media. In Proceedings of the 28th Annual ACM Symposium on User Interface Software \&\#38; Technology (UIST '15). ACM, New York, NY, USA, 280-290. DOI : http://dx.doi .org/10.1145/2807442.2807446 
[18] Germán Leiva and Michel Beaudouin-Lafon. 2018. Montage: A Video Prototyping System to Reduce Re-Shooting and Increase Re-Usability. In Proceedings of the 31st Annual ACM Symposium on User Interface Software and Technology (UIST'18). ACM, New York, NY, USA, 675-682. D0I :

http://dx.doi.org/10.1145/3242587.3242613

[19] James Lin, Mark W. Newman, Jason I. Hong, and James A. Landay. 2001. DENIM: An Informal Tool for Early Stage Web Site Design. In CHI EA '01. ACM, New York, NY, USA, 205-206.

[20] Malcolm McCullough. 2004. Digital Ground: Architecture, Pervasive Computing, and Environmental Knowing. (2004).

[21] Jörn Messeter. 2009. Place-specific computing: A place-centric perspective for digital designs. International Journal of Design 3, 1 (2009).

[22] Elena Márquez Segura, Laia Turmo Vidal, Asreen Rostami, and Annika Waern. 2016. Embodied Sketching. In Proceedings of the 2016 CHI Conference on Human Factors in Computing Systems - CHI'16. ACM Press, Santa Clara, California, USA, 6014-6027. DOI : http://dx.doi.org/10.1145/2858036.2858486

[23] A. F. Newell, A. Carmichael, M. Morgan, and A. Dickinson. 2006. The Use of Theatre in Requirements Gathering and Usability Studies. Interact. Comput. 18, 5 (Sept. 2006), 996-1011. DOI : http://dx.doi.org/10.1016/j.intcom. 2006.05 .003

[24] William Odom, John Zimmerman, Scott Davidoff, Jodi Forlizzi, Anind K. Dey, and Min Kyung Lee. 2012. A Fieldwork of the Future with User Enactments. In Proceedings of the Designing Interactive Systems Conference (DIS '12). ACM, New York, NY, USA, 338-347. DOI :

http://dx.doi.org/10.1145/2317956.2318008

[25] Antti Oulasvirta, Esko Kurvinen, and Tomi Kankainen. 2003. Understanding Contexts by Being There: Case Studies in Bodystorming. Personal Ubiquitous Comput. 7, 2 (July 2003), 125-134. DOI : http://dx.doi.org/10.1007/s00779-003-0238-7

[26] Roman Rädle, Midas Nouwens, Kristian Antonsen, James R. Eagan, and Clemens N. Klokmose. 2017. Codestrates: Literate Computing with Webstrates. In
Proceedings of the 30th Annual ACM Symposium on User Interface Software and Technology (UIST'17). ACM, New York, NY, USA, 715-725. DOI : http://dx.doi.org/10.1145/3126594.3126642

[27] Yvonne Rogers, Kay Connelly, Lenore Tedesco, William Hazlewood, Andrew Kurtz, Robert E. Hall, Josh Hursey, and Tammy Toscos. 2007. Why It's Worth the Hassle: The Value of In-Situ Studies When Designing Ubicomp. In UbiComp 2007: Ubiquitous Computing. Springer, Berlin, Heidelberg, 336-353.

[28] Ugo Braga Sangiorgi, François Beuvens, and Jean Vanderdonckt. 2012. User Interface Design by Collaborative Sketching. In Proceedings of the Designing Interactive Systems Conference (DIS '12). ACM, New York, NY, USA, 378-387. DOI : http://dx.doi.org/10.1145/2317956.2318013

[29] Dennis Schleicher, Peter Jones, and Oksana Kachur. 2010. Bodystorming As Embodied Designing. Interactions 17, 6 (Nov. 2010), 47-51. DOI: http://dx.doi.org/10.1145/1865245.1865256

[30] David Sirkin and Wendy Ju. 2014. Using Embodied Design Improvisation As A Design Research Tool. In Proceedings of the international conference on Human Behavior in Design. Ascona, Switzerland, 7.

[31] Lucy Suchman. 2002. Located accountabilities in technology production. Scandinavian journal of information systems 14, 2 (2002), 7.

[32] John Vines, Tess Denman-Cleaver, Paul Dunphy, Peter Wright, and Patrick Olivier. 2014. Experience Design Theatre: Exploring the Role of Live Theatre in Scaffolding Design Dialogues. In Proceedings of the SIGCHI Conference on Human Factors in Computing Systems (CHI'14). ACM, New York, NY, USA, 683-692. DOI :

http://dx.doi.org/10.1145/2556288.2556960

[33] Zhenpeng Zhao, Sriram Karthik Badam, Senthil Chandrasegaran, Deok Gun Park, Niklas L.E. Elmqvist, Lorraine Kisselburgh, and Karthik Ramani. 2014. skWiki: A Multimedia Sketching System for Collaborative Creativity. In Proceedings of the $32 \mathrm{Nd}$ Annual ACM Conference on Human Factors in Computing Systems (CHI '14). ACM, New York, NY, USA, 1235-1244. DOI :

http://dx.doi.org/10.1145/2556288.2557394 